CIRJE-F-704

\title{
Crude Oil Hedging Strategies Using Dynamic Multivariate GARCH
}

\author{
Roengchai Tansuchat \\ Maejo University \\ Chia-Lin Chang \\ National Chung Hsing University \\ Michael McAleer \\ Erasmus University Rotterdam \\ and Tinbergen Institute \\ January 2010
}

CIRJE Discussion Papers can be downloaded without charge from:

http://www.e.u-tokyo.ac.jp/cirje/research/03research02dp.html

Discussion Papers are a series of manuscripts in their draft form. They are not intended for circulation or distribution except as indicated by the author. For that reason Discussion Papers may not be reproduced or distributed without the written consent of the author. 


\title{
Crude Oil Hedging Strategies Using Dynamic Multivariate GARCH
}

\author{
Roengchai Tansuchat ${ }^{*}$ \\ Faculty of Economics \\ Maejo University \\ Chiang Mai, Thailand \\ Chia-Lin Chang \\ Department of Applied Economics \\ National Chung Hsing University \\ Taichung, Taiwan \\ Michael McAleer \\ Econometrics Institute \\ Erasmus School of Economics \\ Erasmus University Rotterdam \\ and \\ Tinbergen Institute \\ The Netherlands
}

January 2010

*For financial support, the first author is most grateful to the Faculty of Economics, Maejo University, Thailand, the second author would like to acknowledge the National Science Council, Taiwan, and the third author wishes to thank the Australian Research Council, National Science Council, Taiwan, and the Center for International Research on the Japanese Economy (CIRJE), Faculty of Economics, University of Tokyo. 


\begin{abstract}
The paper examines the performance of four multivariate volatility models, namely CCC, VARMA-GARCH, DCC and BEKK, for the crude oil spot and futures returns of two major benchmark international crude oil markets, Brent and WTI, to calculate optimal portfolio weights and optimal hedge ratios, and to suggest a crude oil hedge strategy. The empirical results show that the optimal portfolio weights of all multivariate volatility models for Brent suggest holding futures in larger proportions than spot. For WTI, however, DCC and BEKK suggest holding crude oil futures to spot, but CCC and VARMA-GARCH suggest holding crude oil spot to futures. In addition, the calculated optimal hedge ratios (OHRs) from each multivariate conditional volatility model give the time-varying hedge ratios, and recommend to short in crude oil futures with a high proportion of one dollar long in crude oil spot. Finally, the hedging effectiveness indicates that DCC (BEKK) is the best (worst) model for OHR calculation in terms of reducing the variance of the portfolio.
\end{abstract}

Keywords: Multivariate GARCH, conditional correlations, crude oil prices, optimal hedge ratio, optimal portfolio weights, hedging strategies.

JEL Classifications: C22, C32, G11, G17, G32. 


\section{Introduction}

As the structure of world industries changed in the 1970s, the expansion of the oil market has continually grown to have now become the world's biggest commodity market. This market has developed from a primarily physical product activity into a sophisticated financial market. Over the last decade, crude oil markets have matured greatly, and their range and depth could allow a wide range of participants, such as crude oil producers, crude oil physical traders, and refining and oil companies, to hedge oil price risk. Risk in the crude oil commodity market is likely to occur due to unexpected jumps in global oil demand, a decrease in the capacity of crude oil production and refinery capacity, petroleum reserve policy, OPEC spare capacity and policy, major regional and global economic crises, and geopolitical risks.

A futures contract is an agreement between two parties to buy and sell a given amount of a commodity at an agreed upon certain date in the future, at an agreed upon price, and at a given location. Furthermore, a futures contract is the instrument primarily designed to minimize one's exposure to unwanted risk. Futures traders are traditionally placed in one of two groups, namely hedgers and speculators. Hedgers typically include producers and consumers of a commodity, or the owners of an asset, who have an interest in the underlying asset, and are attempting to offset exposure to price fluctuations in some opposite position in another market. Unlike hedgers, speculators do not intend to minimize risk but rather to make a profit from the inherently risky nature of the commodity market by predicting market movements. Hedger want to minimize risk, regardless of what they are investing in, while speculators want to increase their risk and thereby maximize profits.

Conceptually, hedging through trading futures contracts is a procedure used to restrain or reduce the risk of unfavourable price changes because cash and futures prices for the same commodity tend to move together. Therefore, changes in the value of a cash position are offset by changes in the value of an opposite futures position. In addition, futures contracts are favoured as a hedging tool because of their liquidity, speed and lower transaction costs. 
Among the industries and firms that are more likely to use a hedging strategy is the oil and gas industry. Firms will hedge only if they expect that an unfavourable event will arise. Knill et al. (2006) suggested that if an oil and gas company uses futures contracts to hedge risk, they hedge only the downside risk. When an industry perspective is good (bad), they will scale down (up) on their futures usage, thereby pushing futures prices higher (lower). Hedging by the crude oil producers normally involves selling the commodity futures because producers or refiners use futures contracts to lock the futures selling prices or a price floor. Thus, they tend to take short positions in futures. At the same time, energy traders, investors or fuel oil users focusing to lock in a futures purchase price or price ceiling tend to long positions in futures. Daniel (2001) shows that hedging strategies can substantially reduce oil price volatility without significantly reducing returns, and with the added benefit of greater predictability and certainty.

Theoretically, issues in hedging involve the determination of the optimal hedge ratio (OHR). One of the most widely-used hedging strategies is based on the minimization of the variance of the portfolio, the so-called minimum variance hedge ratio (see Chen et al. (2003) for a review of the futures hedge ratio, and Lien and Tse (2002) for some recent developments in futures hedging). With the minimum-variance criterion, risk management requires determination of the OHR (the optimal amount of futures bought or sold expressed as a proportion of the cash position). In order to estimate such a ratio, early research simply used the slope of the classical linear regression model of cash on the futures price, which assumed a time-invariant hedge ratio (see, for example, Ederington (1979), Figlewski (1985), and Myers and Thomson (1989)). However, it is now widely agreed that financial asset returns volatility, covariancec and correlations are time-varying with persistent dynamics, and rely on techniques such as conditional volatility (CV) and stochastic volatility (SV) models. Baillie and Myers (1991) claim that, if the joint distribution of cash prices and futures prices changes over time, estimating a constant hedge ratio may not be appropriate. In this paper, time-varying hedge ratios are estimated and analysed.

The widely used ARCH and GARCH models appear to be ideal for estimating time-varying OHRs, and a number of applications have concluded that such ratios seem to display considerable variability over time (see, for example, Cecchetti et al. (1988), Baillie and Myers (1991), Myers (1991), and Kroner and Sultan (1993)). Typically, the hedging model is 
constructed for a decision maker who allocates wealth between a risk-free asset and two risky assets, namely the physical commodity and the corresponding futures. OHR is defined as $\operatorname{OHR}_{t}=\operatorname{cov}\left(p_{t}, f_{t} \mid F_{t-1}\right) / \operatorname{var}\left(f_{t} \mid F_{t-1}\right)$, where $p_{t}$ and $f_{t}$ are futures price and spot price, respectively, and $F_{t-1}$ is the information set. Therefore, $\mathrm{OHR}_{t}$ can be calculated given the knowledge of the time-dependent covariance matrix for cash and futures prices, which can be estimated using multivariate GARCH models.

In the literature, research has been conducted on the volatility of crude spot, forward and futures returns. Lanza et al. (2006) applied the constant conditional correlation (CCC) model of Bollerslev (1990) and the dynamic conditional correlation (DCC) model of Engle (2002) for West Texas Intermediate (WTI) oil forward and futures returns. Manera et al. (2006) used CCC, the vector autoregressive moving average (VARMA-GARCH) model of Ling and McAleer (2003), the VARMA- Asymmetric GARCH model of McAleer et al. (2009), and DCC to spot and forward return in the Tapis market. Recently, Chang et al. (2009a, 2009b, 2009c) estimated multivariate conditional volatility and examined volatility spillovers for the returns on spot, forward and futures returns for Brent, WTI, Dubai and Tapis to aid risk diversification in crude oil markets. However, these authors did not focus on OHR or the design of an optimal hedging strategy based on a wide range of models.

For estimated time-varying hedge ratios using multivariate conditional volatility models, Haigh and Holt (2002) modelled the time-varying hedge ratio among crude oil (WTI), heating oil and unleaded gasoline futures contracts in reducing price volatility for an energy trader with the BEKK model of Engle and Kroner (1995), and accounted for volatility spillovers. Alizadeh et al. (2004) examined appropriate futures contracts, and examine the effectiveness of hedging marine bunker price fluctuations in Rotterdam, Singapore and Houston using different crude oil and petroleum futures contracts traded on the New York Mercantile Exchange (NYMEX) and the International Petroleum Exchange (IPE) in London, using the VECM and BEKK models. Jalali-Naini and Kazemi-Manesh (2006) examined hedge ratios using weekly spot prices of WTI and futures prices of crude oil contracts one month to four months on NYMEX. The results from the BEKK model showed that the OHRs are time varying for all contracts, and higher duration contracts had higher perceived risk, a higher OHR mean, and standard deviations. 
The purpose of this paper is to estimate multivariate conditional volatility models, namely CCC, VARMA-GARCH, DCC and BEKK, for the returns on spot and futures prices for Brent and WTI markets, to calculate the optimal portfolio weights and OHRs ratio from the conditional covariance matrices for effective optimal portfolio designs and hedging strategies, and to investigate and compare the performance of OHRs from estimated multivariate conditional volatility models by applying the hedging effectiveness index.

The structure of the remainder of the paper is as follows. Section 2 discusses the multivariate GARCH models to be estimated, and the derivation of the OHR and hedging effective index. Section 3 describes the data, descriptive statistics and unit root test statistics. Section 4 analyses the empirical estimates from empirical modelling. Some concluding remarks are given in Section 5.

\section{Econometric Models}

\subsection{Multivariate Conditional Volatility Models}

This section presents the CCC model of Bollerslev (1990), VARMA-GARCH model of Ling and McAleer (2003), VARMA-AGARCH model of McAleer et al. (2009), DCC model of Engle (2002), and BEKK model of Engle and Kroner (1995). The first three models assume constant conditional correlations, while the last two models accommodate dynamic conditional correlations.

Consider the CCC multivariate GARCH model of Bollerslev (1990):

$$
\begin{gathered}
y_{t}=E\left(y_{t} \mid F_{t-1}\right)+\varepsilon_{t}, \quad \varepsilon_{t}=D_{t} \eta_{t} \\
\operatorname{var}\left(\varepsilon_{t} \mid F_{t-1}\right)=D_{t} \Gamma D_{t}
\end{gathered}
$$

Where $y_{t}=\left(y_{1 t}, \ldots, y_{m t}\right)^{\prime}, \eta_{t}=\left(\eta_{1 t}, \ldots, \eta_{m t}\right)^{\prime}$ is a sequence of independently and identically distributed (i.i.d.) random vectors, $F_{t}$ is the past information available at time $t$, 
$D_{t}=\operatorname{diag}\left(h_{1}^{1 / 2}, \ldots, h_{m}^{1 / 2}\right), m$ is the number of returns, and $t=1, \ldots, n$, (see, for example, McAleer 92005) and Bauwens, et al. (2006)). As $\Gamma=E\left(\eta_{t} \eta_{t}^{\prime} \mid F_{t-1}\right)=E\left(\eta_{t} \eta^{\prime}\right)$, where $\Gamma=\left\{\rho_{i j}\right\}$ for $i, j=1, \ldots, m$, the constant conditional correlation matrix of the unconditional shocks, $\eta_{t}$, is equivalent to the constant conditional covariance matrix of the conditional shocks, $\varepsilon_{t}$, from (1), $\quad \varepsilon_{t} \varepsilon_{t}^{\prime}=D_{t} \eta_{t} \eta_{t}^{\prime} D_{t}, \quad D_{t}=\left(\operatorname{diag} Q_{t}\right)^{1 / 2}$, and $E\left(\varepsilon_{t} \varepsilon_{t}^{\prime} \mid F_{t-1}\right)=Q_{t}=D_{t} \Gamma D_{t}$, where $Q_{t}$ is the conditional covariance matrix.

The CCC model of Bollerslev (1990) assumes that the conditional variance for each return, $h_{i t}, i=1, . ., m$, follows a univariate GARCH process, that is

$$
h_{i t}=\omega_{i}+\sum_{j=1}^{r} \alpha_{i j} \varepsilon_{i, t-j}^{2}+\sum_{j=1}^{s} \beta_{i j} h_{i, t-j}
$$

where $\alpha_{i j}$ represents the ARCH effect, or short run persistence of shocks to return $i, \beta_{i j}$ represents the GARCH effect, and $\sum_{j=1}^{r} \alpha_{i j}+\sum_{j=1}^{s} \beta_{i j}$ denotes the long run persistence.

In order to accommodate interdependencies of volatility across different assets and/or markets, Ling and McAleer (2003) proposed a vector autoregressive moving average (VARMA) specification of the conditional mean, and the following specification for the conditional variance:

$$
\begin{gathered}
Y_{t}=E\left(Y_{t} \mid F_{t-1}\right)+\varepsilon_{t} \\
\Phi(L)\left(Y_{t}-\mu\right)=\Psi(L) \varepsilon_{t} \\
\varepsilon_{t}=D_{t} \eta_{t} \\
H_{t}=W_{t}+\sum_{l=1}^{r} A_{t} \vec{\varepsilon}_{t-l}+\sum_{l=1}^{s} B_{l} H_{i, t-l}
\end{gathered}
$$


where $W_{t}, A_{l}$ and $B_{l}$ are $m \times m$ matrices, with typical elements $\alpha_{i j}$ and $\beta_{i j}$, respectively. $H_{t}=\left(h_{1 t}, \ldots, h_{m t}\right)^{\prime}, \quad \vec{\varepsilon}=\left(\varepsilon_{1 t}^{2}, \ldots \varepsilon_{m t}^{2}\right)^{\prime}, \quad \Phi(L)=I_{m}-\Phi_{1} L-\ldots-\Phi_{p} L^{p}$ and $\Psi(L)=I_{m}-\Psi_{1} L-\ldots$ $-\Psi_{q} L^{q}$ are polynomials in $L$, the lag operator. It is clear that when $A_{l}$ and $B_{l}$ are diagonal matrices, (6) reduces to (2)

The VARMA-GARCH model assumes that negative and positive shocks of equal magnitude have identical impacts on the conditional variance. McAleer et al. (2009) extended the VARMA-GARCH to accommodate the asymmetric impacts of the unconditional shocks on the conditional variance, and proposed the VARMA-AGARCH specification of the conditional variance as follows:

$$
H_{t}=W+\sum_{i=1}^{r} A_{i} \vec{\varepsilon}_{t-i}+\sum_{i=1}^{r} C_{i} I_{t-i} \vec{\varepsilon}_{t-i}+\sum_{j=1}^{s} B_{j} H_{t-j}
$$

where $C_{i}$ are $m \times m$ matrices for $i=1, . ., r$ with typical element $\gamma_{i j}$, and $I_{t}=\operatorname{diag}\left(I_{1 t}, \ldots, I_{m t}\right)$, is an indicator function, given as

$$
I\left(\eta_{i t}\right)= \begin{cases}0, & \varepsilon_{i t}>0 \\ 1, & \varepsilon_{i t} \leq 0\end{cases}
$$

If $m=1$, (7) collapses to the asymmetric GARCH (or GJR) model of Glosten et al. (1992). Moreover, VARMA-AGARCH reduces to VARMA-GARCH when $C_{i}=0$ for all $i$. If $C_{i}=0$ and $A_{i}$ and $B_{j}$ are diagonal matrices for all $i$ and $j$, then VARMA-AGARCH reduces to the CCC model. The structural and statistical properties of the model, including necessary and sufficient conditions for stationarity and ergodicity of VARMA-GARCH and VARMAAGARCH, are explained in detail in Ling and McAleer (2003) and McAleer et al. (2009), respectively. The parameters of model (1)-(7) are obtained by maximum likelihood estimation (MLE) using a joint normal density. When $\eta_{t}$ does not follow a joint multivariate normal distribution, the appropriate estimator is QMLE. 
The assumption that the conditional correlations are constant may seem unrealistic in many empirical results, particularly in previous studies about crude oil returns (see, for example, Lanza et al. (2006), Manera et al. (2006), and Chang et al. (2009a, 2009b, 2009c)). In order to make the conditional correlation matrix time dependent, Engle (2002) proposed a dynamic conditional correlation (DCC) model, which is defined as

$$
\begin{aligned}
& y_{t} \mid \mathfrak{J}_{t-1} \square\left(0, Q_{t}\right) \quad, \quad t=1,2, \ldots, n \\
& Q_{t}=D_{t} \Gamma_{t} D_{t},
\end{aligned}
$$

where $D_{t}=\operatorname{diag}\left(h_{1}^{1 / 2}, \ldots, h_{m}^{1 / 2}\right)$ is a diagonal matrix of conditional variances, and $\mathfrak{J}_{t}$ is the information set available at time $t$. The conditional variance, $h_{i t}$, can be defined as a univariate GARCH model, as follows:

$$
h_{i t}=\omega_{i}+\sum_{k=1}^{p} \alpha_{i k} \varepsilon_{i, t-k}+\sum_{l=1}^{q} \beta_{i l} h_{i, t-l} .
$$

If $\eta_{t}$ is a vector of i.i.d. random variables, with zero mean and unit variance, $Q_{t}$ in (12) is the conditional covariance matrix (after standardization, $\eta_{i t}=y_{i t} / \sqrt{h_{i t}}$ ). The $\eta_{i t}$ are used to estimate the dynamic conditional correlations, as follows:

$$
\Gamma_{t}=\left\{( \operatorname { d i a g } ( Q _ { t } ) ^ { - 1 / 2 } \} Q _ { t } \left\{\left(\operatorname{diag}\left(Q_{t}\right)^{-1 / 2}\right\}\right.\right.
$$

where the $k \times k$ symmetric positive definite matrix $Q_{t}$ is given by

$$
Q_{t}=\left(1-\theta_{1}-\theta_{2}\right) \bar{Q}+\theta_{1} \eta_{t-1} \eta_{t-1}^{\prime}+\theta_{2} Q_{t-1}
$$

in which $\theta_{1}$ and $\theta_{2}$ are scalar parameters to capture the effects of previous shocks and previous dynamic conditional correlations on the current dynamic conditional correlation, and $\theta_{1}$ and $\theta_{2}$ are non-negative scalar parameters. When $\theta_{1}=\theta_{2}=0, \bar{Q}$ in (13) is equivalent 
to CCC. As $Q_{t}$ is a conditional on the vector of standardized residuals, (13) is a conditional covariance matrix, and $\bar{Q}$ is the $k \times k$ unconditional variance matrix of $\eta_{t}$. DCC is not linear, but may be estimated simply using a two-step method based on the likelihood function, the first step being a series of univariate GARCH estimates and the second step being the correlation estimates (see Caproin and McAleer 92009) for further details and caveats).

An alternative dynamic conditional model is BEKK, which has the attractive property that the conditional covariance matrices are positive definite. However, BEKK suffers from the socalled "curse of dimentionality" (see McAleer et al. (2009) for a comparison of the number of parameters in various multivariate conditional volatility models). The BEKK model for multivariate $\operatorname{GARCH}(1,1)$ is given as:

$$
\mathbf{H}_{t}=\mathbf{C}^{\prime} \mathbf{C}+\mathbf{A}^{\prime} \varepsilon_{t-1} \varepsilon_{t-1}^{\prime} \mathbf{A}+\mathbf{B}^{\prime} \mathbf{H}_{t-1} \mathbf{B}
$$

where the individual element for the matrices $\mathbf{C}, \mathbf{A}$ and $\mathbf{B}$ matrices are given as

$$
\mathbf{A}=\left[\begin{array}{ll}
a_{11} & a_{12} \\
a_{21} & a_{22}
\end{array}\right], \quad \mathbf{B}=\left[\begin{array}{ll}
b_{11} & b_{12} \\
b_{21} & b_{22}
\end{array}\right], \quad \mathbf{C}=\left[\begin{array}{ll}
c_{11} & 0 \\
c_{21} & c_{22}
\end{array}\right]
$$

with $\alpha_{i i}^{2}+\beta_{i i}^{2}<1, i=1,2$ for stationarity. In this diagonal representation, the conditional variances are functions of their own lagged values and own lagged returns shocks, while the conditional covariances are functions of the lagged covariances and lagged cross-products of the corresponding returns shocks. Moreover, this formulation guarantees $\mathbf{H}_{t}$ to be positive definite almost surely for all $t$. For further details and a comparison between BEKK and DCC, see Caporin and McAleer (2008, 2009).

\subsection{Optimal Hedge Ratios and Optimal Portfolio Weights}

Market participants in futures markets choose a hedging strategy that reflects their attitudes toward risk and their individual goals. Consider the case of an oil company, which usually 
wants to protect exposure to crude oil price fluctuations. The return on the oil company's portfolio of spot and futures position can be denoted as:

$$
R_{H, t}=R_{S, t}-\gamma_{t} R_{F, t}
$$

where $R_{H, t}$ is the return on holding the portfolio between $t-1$ and $t, R_{S, t}$ and $R_{F, t}$ are the returns on holding spot and futures positions between $t$ and $t-1$, and $\gamma$ is the hedge ratio, that is, the number of futures contracts that the hedger must sell for each unit of spot commodity on which price risk is borne.

According to Johnson (1960), the variance of the returns of the hedged portfolio, conditional on the information set available at time $t-1$, is given by

$$
\operatorname{var}\left(R_{H, t} \mid \Omega_{t-1}\right)=\operatorname{var}\left(R_{S, t} \mid \Omega_{t-1}\right)-2 \gamma_{t} \operatorname{cov}\left(R_{S, t}, R_{F, t} \mid \Omega_{t-1}\right)+\gamma_{t}^{2} \operatorname{var}\left(R_{F, t} \mid \Omega_{t-1}\right),
$$

where $\operatorname{var}\left(R_{S, t} \mid \Omega_{t-1}\right), \operatorname{var}\left(R_{F, t} \mid \Omega_{t-1}\right)$ and $\operatorname{cov}\left(R_{S, t}, R_{F, t} \mid \Omega_{t-1}\right)$ are the conditional variance and covariance of the spot and futures returns, respectively. The OHRs are defined as the value of $\gamma_{t}$ which minimizes the conditional variance (risk) of the hedged portfolio returns, that is, $\min _{\gamma_{t}}\left[\operatorname{var}\left(R_{H, t} \mid \Omega_{t-1}\right)\right]$. Taking the partial derivative of (16) with respect to $\gamma_{t}$, setting it equal to zero and solving for $\gamma_{t}$, yields the $\mathrm{OHR}_{t}$ conditional on the information available at $t-1$ (see, for example, Baillie and Myers (1991)):

$$
\gamma_{t}^{*} \mid \Omega_{t-1}=\frac{\operatorname{cov}\left(R_{S, t}, R_{F, t} \mid \Omega_{t-1}\right)}{\operatorname{var}\left(R_{F, t} \mid \Omega_{t-1}\right)}
$$

where returns are defined as the logarithmic differences of spot and futures prices.

From the multivariate conditional volatility model, the conditional covariance matrix is obtained, such that the OHR is given as: 


$$
\gamma_{t}^{*} \mid \Omega_{t-1}=\frac{h_{S F, t}}{h_{F, t}}
$$

where $h_{S F, t}$ is the conditional covariance between spot and futures returns, and $h_{F, t}$ is the conditional variance of futures returns.

In order to compare the performance of OHRs obtained from different multivariate conditional volatility models, $\mathrm{Ku}$ et al. (2007) suggest that a more accurate model of conditional volatility should also be superior in terms of hedging effectiveness, as measured by the variance reduction for any hedged portfolio compared with the unhedged portfolio. Thus, a hedging effective index (HE) is given as:

$$
\mathrm{HE}=\left[\frac{\mathrm{var}_{\text {unhedged }}-\mathrm{var}_{\text {hedged }}}{\text { var }_{\text {unhedged }}}\right] \text {, }
$$

where the variances of the hedge portfolio are obtained from the variance of the rate of return, $R_{H, t}$, and the variance of the unhedged portfolio is the variance of spot returns (see, for example, Ripple and Moosa (2007)). A higher HE indicates a higher hedging effectiveness and larger risk reduction, such that a hedging method with a higher HE is regarded as a superior hedging strategy.

Alternatively, in order to construct an optimal portfolio design that minimizes risk without lowering expected returns, and applying the methods of Kroner and $\mathrm{Ng}$ (1998) and Hammoudeh et al. (2009), the optimal portfolio weight of crude oil spot/futures holding is given by:

$$
w_{S F, t}=\frac{h_{F, t}-h_{S F, t}}{h_{S, t}-2 h_{S F, t}+h_{F, t}}
$$

and 


$$
w_{S F, t}= \begin{cases}0, & \text { if } w_{S F, t}<0 \\ w_{S F, t}, & \text { if } 0<w_{S F, t}<0 \\ 1, & \text { if } w_{S F, t}>0\end{cases}
$$

where $w_{S F, t}\left(1-w_{S F, t}\right)$ is the weight of the spot (futures) in a one dollar portfolio of crude oil spot/futures at time $t$.

\section{Data}

Daily synchronous closing prices of spot and futures crude oil prices from two major crude oil markets, namely Brent and WTI, are used in the empirical analysis. The 3,132 price observations from 4 November 1997 to 4 November 2009 are obtained from the DataStream database. The returns of crude oil prices $i$ of market $j$ at time $t$ in a continuous compound basis are calculated as $r_{i j, t}=\log \left(P_{i j, t} / P_{i j, t-1}\right)$, where $P_{i j, t}$ and $P_{i j, t-1}$ are the closing prices of crude oil price $i$ in market $j$ for days $t$ and $t-1$, respectively.

Table 1 presents the descriptive statistics for the returns series of crude oil prices. The average returns of spot and futures in Brent and WTI are similar and very low, but the corresponding variance of returns is much higher. These crude oil returns series have high kurtosis, which indicates the presence of fat tails. The negative skewness statistics signify the series has a longer left tail (extreme losses) than right tail (extreme gains). The Jarque-Bera Lagrange multiplier statistics of crude oil returns in each market are statistically significant, thereby implying that the distribution of these prices is not normal. Based on the coefficient of variation, the historical volatility among all crude oil returns are not especially different.

\section{[Insert Table 1 here]}

Figure 1 presents the plot of synchronous crude oil price prices. All prices move in the same pattern, suggesting they are contemporaneously highly correlated. The calculated contemporaneous correlations between crude oil spot and futures returns for Brent and WTI markets are both 0.99 . Figure 2 shows the plot of crude oil returns. These indicate volatility clustering, or periods of high volatility followed by periods of relative tranquility. Figure 3 
displays the volatilities of crude oil returns, where volatilities are calculated as the square of the estimated residuals from an ARMA(1,1) process. These plots are similar in all four returns, with volatility clustering and an apparent outlier.

\section{[Insert Figures 1-3 here]}

Standard econometric practice in the analysis of financial time series data begins with an examination of unit roots. The Augmented Dickey-Fuller (ADF) and Phillips-Perron (PP) tests are used to test for all crude oil returns in each market under the null hypothesis of a unit root against the alternative hypothesis of stationarity. The results from unit root tests are presented in Table 2. The tests yield large negative values in all cases for levels, such that the individual returns series reject the null hypothesis at the $1 \%$ significance level, so that all returns series are stationary.

\section{[Insert Table 2 here]}

\section{Empirical Results}

An important task is to model the conditional mean and conditional variances of the returns series. Therefore, univariate ARMA-GARCH models are estimated, with the appropriate univariate conditional volatility model given as ARMA(1,1)-GARCH(1,1). These results are available upon request. All multivariate conditional volatility models in this paper are estimated using the RATS 6.2 econometric software package.

Table 3 presents the estimates for the CCC model, with $p=q=r=s=1$. The two entries corresponding to each of the parameters are the estimate and the Bollerslev-Wooldridge (1992) robust $t$-ratios. The ARCH and GARCH estimates of the conditional variance between crude oil spot and futures returns in Brent and WTI are statistically significant. The ARCH $(\alpha)$ estimates are generally small (less than 0.1 ), and the GARCH $(\beta)$ estimates are generally high and close to one. Therefore, the long run persistence, is generally close to one, indicating a near long memory process. In addition, since $\alpha+\beta<1$, all markets satisfy the second moment and log-moment condition, which is a sufficient condition for the QMLE to be consistent and asymptotically normal (see McAleer, Chan and Marinova (2007)). The 
CCC estimates between the volatility of spot and futures returns of Brent and WTI are high, with the highest being 0.923 between the standardized shocks to volatility in the crude oil spot and futures returns of the WTI market.

\section{[Insert Table 3 here]}

Table 4 reports the estimates of the conditional mean and variance for $\operatorname{VARMA}(1,1)$ $\operatorname{GARCH}(1,1)$ models. The ARCH $(\alpha)$ and GARCH $(\beta)$ estimates, which refer to the own past shocks and volatility effects, respectively, are statistically significant in all markets. The degree of short run persistence, $\alpha$, varies across those returns. In the case of the Brent market, the shock dependency in the short run of futures returns $(0.100)$ is higher than that of spot returns (0.069). In the WTI market, spot returns (0.211) are higher than futures returns (0.066). However, the degree of long run persistence, $\alpha+\beta$, of futures returns in both markets is higher than for spot returns. This indicates that convergence to the long run equilibrium after shocks to futures returns is faster than for spot returns. Moreover, volatility spillover effects between volatility of spot and futures returns are found in both markets, especially the interdependency of spot and futures returns in the Brent market, 0.712 and 0.212. This means that the conditional variances of spot and futures returns of the Brent market are affected by the previous long run shocks from each other, while the conditional variance of spot returns is only affected by the previous long run shocks from futures returns, 0.654 in the case of the WTI market.

\section{[Insert Table 4 here]}

The DCC estimates of the conditional correlations between the volatilities of spot and futures returns based on estimating the univariate $\operatorname{GARCH}(1,1)$ model for each market are given in Table 5. Based on the Bollerslev and Wooldridge (1992) robust $t$-ratios, the estimates of the

DCC parameters, $\hat{\theta}_{1}$ and $\hat{\theta}_{2}$, are statistically significant in all cases. This indicates that the assumption of constant conditional correlation for all shocks to returns is not supported empirically. The short run persistence of shocks on the dynamic conditional correlations is greatest for WTI at 0.139 , while the largest long run persistence of shocks to the conditional correlations is $0.986(=0.070+0.916)$ for Brent. 
The time-varying conditional correlations between spot and futures returns are given in Figure 4. It is clear that there is significant variation in the conditional correlations over time, especially the spot and futures returns of Brent. The estimates for BEKK are given in Table 6. The elements of the $2 \times 2$ parameter matrices, $\mathbf{A}$ and $\mathbf{B}$, are statistically significant.

\section{[Insert Tables 5 and 6 here] [Insert Figure 4 here]}

Table 7 gives the optimal portfolio weights, OHRs and hedge effectiveness. The average value of $w_{S F, t}$, calculated from (20) and (21), based on the Brent and WTI markets, are reported in the first and second columns. In the case of the Brent market, the optimal portfolio weights from each model are not particularly different, suggesting that the portfolio constructions give similar results. For example, the largest average value of $w_{S F, t}$ of the portfolio comprising crude oil spot and futures from the CCC model is 0.383 , meaning that investors should have more crude oil futures than spot in their portfolio in order to minimize risk without lowering expected returns. In addition, the optimal holding of spot in one dollar of crude oil spot/futures portfolio is 38.3 cents, and 61.7 cents for futures.

\section{[Insert Table 7 here]}

In the case of the WTI market, optimal portfolio weights from constant conditional correlation models, namely CCC and VARMA-GARCH, are different and smaller than those from the dynamic conditional correlation models, namely DCC and BEKK. For example, the largest $w_{S F, t}$ is 0.571 from the BEKK model, while the smallest $w_{S F, t}$ is 0.350 from the CCC model, thereby signifying that the dynamic conditional correlation models suggest holding crude oil spot (57.1 cents for spot) more than futures (42.9 cents for futures), whereas the constant conditional correlation models suggest holding crude oil futures (65 cents for futures) than spot (35 cents for futures) of a one dollar spot/futures portfolio.

Figure 5 presents the calculated time-varying OHRs from each multivariate conditional volatility model. There are clearly time-varying hedge ratios. The third and fourth columns in 
Table 7 report the average OHR values. The average OHR values of the Brent market obtained from several different multivariate conditional volatility models are high and have similar patterns to those of the WTI market. Following from the hedge strategy, for example, the largest average OHR values are 0.846 and 0.956 from VARMA-GARCH of Brent and WTI suggests that one dollar long (buy) in the crude oil spot should be shorted (sold) by about 84.6 and 95.6 cents of futures, respectively. In addition, the constant conditional correlations of both markets recommend to short futures as compared with the dynamic conditional correlations.

\section{[Insert Figure 5 here]}

The hedging effectiveness in columns five and six in Table 7 shows that all four multivariate conditional volatility models effectively reduce the variances of the portfolio, and perform better in the WTI market than the Brent market (the HE indices are around 80\% for WTI and $56 \%$ for Brent). Of the multivariate GARCH models, the largest HE value of the Brent market (WTI market) is obtained from DCC, such that DCC is the best model for OHR calculation in terms of the variance of portfolio reduction. In contrast, the lowest HE value in both markets is obtained from BEKK model. Therefore, the BEKK model is the worst model in terms of the variance of portfolio reduction.

\section{Conclusion}

This paper estimated four multivariate volatility models, namely CCC, VARMA-GARCH, DCC and BEKK, for the crude oil spot and futures returns of two major benchmark international crude oil markets, namely Brent and WTI. The estimated conditional covariance matrices from these models were used to calculate the optimal portfolio weights and optimal hedge ratios, and to indicate crude oil hedge strategies. Moreover, in order to compare the ability of variance portfolio reduction due to different multivariate volatility models, the hedging effective index was also estimated.

The empirical results for daily data from 4 November 1997 to 4 November 2009 showed that, for the Brent market, the optimal portfolio weights of all multivariate volatility models suggested holding futures in larger proportion than spot. On the contrary, for the WTI market, 
the dynamic conditional correlations models, DCC and BEKK, recommended holding futures to spot, but the constant conditional correlation models, CCC and VARMA-GARCH, suggested holding spot to futures. The calculated OHRs from each multivariate conditional volatility model presented the time-varying hedge ratios, and recommended to short in crude oil futures, with a high proportion of one dollar long in crude oil spot. The hedging effectiveness indicated that DCC (BEKK) was the best (worst) model for OHR calculation in terms of the variance of portfolio reduction. 


\section{References}

Alizadeh, A.H., M.G. Kavussanos and D.A. Menachof (2004), Hedging against bunker price fluctuations using petroleum futures contract: Constant versus time-varying hedge ratios, Applied Economics, 36, 1337-1353.

Baillie, R. and R. Myers (1991), Bivariate GARCH estimation of the optimal commodity futures hedge, Journal of Applied Econometrics, 6, 109-124.

Bauwens, L., S. Laurent and J. Rombouts (2006), Multivariate GARCH models: A survey, Journal of Applied Econometrics, 21, 79-109.

Bollerslev, T. (1986), Generalised autoregressive conditional heteroscedasticity, Journal of Econometrics, 31, 307-327.

Bollerslev, T. (1990), Modelling the coherence in short-run nominal exchange rate: A multivariate generalized ARCH approach, Review of Economics and Statistics, 72, 498-505.

Bollerslev, T. and J. Wooldridge (1992), Quasi-maximum likelihood estimation and inference in dynamic models with time-varying covariances, Econometric Reviews, 11, 143172.

Caporin, M. and M. McAleer (2008), Scalar BEKK and indirect DCC, Journal of Forecasting, 27, 537-549

Caporin, M. and M. McAleer (2009), Do we really need both BEKK and DCC? A tale of two covariance models, Available at SSRN: http://ssrn.com/abstract=1338190.

Cecchetti, S., R. Cumby, and S. Figlewski (1988), Estimation of the optimal futures hedge, Review of Economics and Statistics, 70, 623-630.

Chang, C.-L., M. McAleer and R. Tansuchat (2009a), Modeling conditional correlations for risk diversification in crude oil markets, to appear in Journal of Energy Markets, Available at SSRN: http://ssrn.com/abstract=1401331.

Chang, C.-L., M. McAleer and R. Tansuchat (2009b), Forecasting volatility and spillovers in crude oil spot, forward and futures market, Available at SSRN: http://ssrn.com/abstract=1402164.

Chang, C.-L., M. McAleer and R. Tansuchat (2009c), Volatility spillovers between returns on crude oil futures and oil company stocks, Available at SSRN: http://ssrn.com/abstract=1406983. 
Chen, S.-S., C.-F. Lee and K. Shrestha (2003), Futures hedge ratios: A review, Quarterly Review of Economics and Finance, 43, 433-465.

Daniel, J. (2001), Hedging government oil price risk, IMF Working Paper 01/185.

Ederington, L.H. (1979), The hedging performance of the new futures markets, Journal of Finance, 34, 157-170.

Engle, R. (2002), Dynamic conditional correlation: A simple class of multivariate generalized autoregressive conditional heteroskedasticity models, Journal of Business and Economic Statistics. 20, 339-350.

Engle, R.F. and K.F. Kroner (1995), Multivariate simultaneous generalized ARCH, Econometric Theory, 11, 122-150.

Figlewski, S. (1985), Hedging with stock index futures: estimation and forecasting with error correction model, Journal of Futures Markets, 13, 743-752.

Glosten, L., R. Jagannathan and D. Runkle (1992), On the relation between the expected value and volatility of nominal excess return on stocks, Journal of Finance, 46, 17791801.

Haigh, M.S. and M. Holt (2002), Crack spread hedging: Accounting for time-varying spillovers in the energy futures markets, Journal of Applied Econometrics, 17, 269289.

Hammoudeh, S., Y. Yuan, M. McAleer and M.A. Thompson (2009), Precious metalsexchange rate volatility transmission and hedging strategies, Available at SSRN: http://ssrn.com/abstract=1495748.

Jalali-Naini, A. and M. Kazemi-Manesh (2006), Price volatility, hedging, and variable risk premium in the crude oil market, OPEC Review, 30(2), 55-70.

Johnson, L.L. (1960), The theory of hedging and speculation in commodity futures, Review of Economic Studies, 27, 139-151.

Knill, A., M. Kristina and A. Nejadmalayeri (2006), Selective hedging, information, asymmetry, and futures prices, Journal of Business, 79(3), 1475-1501.

Kroner, K. and V. Ng (1998), Modeling asymmetric movements of asset prices, Review of Financial Studies, 11, 871-844

Kroner, K. and J. Sultan (1993), Time-varying distributions and dynamic hedging with foreign currency futures, Journal of Financial and Quantitative Analysis, 28, 535551. 
Ku, Y.-H., H.-C. Chen and K.-H. Chen (2007), On the application of the dynamic conditional correlation model in the estimating optimal time-varying hedge ratios, Applied Economics Letter, 14, 503-509.

Lanza, A., M. Manera and M. McAleer (2006), Modeling dynamic conditional correlations in WTI oil forward and future returns, Finance Research Letters, 3, 114-132.

Lien, D. and Y.K. Tse (2002), Some recent developments in futures hedging, Journal of Economic Surveys, 16(3), 357-396.

Ling, S. and M. McAleer (2003), Asymptotic theory for a vector ARMA-GARCH model, Econometric Theory, 19, 278-308.

Manera, M., M. McAleer and M. Grasso (2006), Modelling time-varying conditional correlations in the volatility of Tapis oil spot and forward returns, Applied Financial Economics, 16, 525-533.

McAleer, M. (2005), Automated inference and learning in modeling financial volatility, Econometric Theory, 21, 232-261.

McAleer, M., F. Chan and D. Marinova (2007), An econometric analysis of asymmetric volatility: Theory and application to patents, Journal of Econometrics, 139, 259-284

McAleer, M., S. Hoti and F. Chan (2009), Structure and asymptotic theory for multivariate asymmetric conditional volatility, Econometric Reviews, 28, 422-440.

Myers, R. (1991), Estimating time varying hedge ratio on futures markets, Journal of Futures Markets, 11, 39-53.

Myers, R. and S. Thompson (1989), Generalized optimal hedge ratio estimation, American Journal of Agricultural Economics, 71, 858-868.

Ripple, R.D. and I.A. Moosa (2007), Hedging effectiveness and futures contract maturity: The case of NYMEX crude oil futures, Applied Financial Economics, 17, 683-689. 
Table 1. Descriptive Statistics

\begin{tabular}{lcccccccc}
\hline Returns & Mean & Max & Min & SD & CV & Skewness & Kurtosis & Jarque-Bera \\
\hline BRSP & 0.0004 & 0.152 & -0.170 & 0.025 & 0.016 & -0.047 & 6.113 & 1265.547 \\
BRFU & 0.0004 & 0.129 & -0.144 & 0.024 & 0.017 & -0.142 & 5.576 & 876.642 \\
WTISP & 0.0004 & 0.213 & -0.172 & 0.027 & 0.015 & -0.002 & 7.932 & 3174.982 \\
WTIFU & 0.0004 & 0.164 & -0.165 & 0.025 & 0.016 & -0.120 & 7.164 & 2270.166 \\
\hline
\end{tabular}


Table 2. Unit Root Tests

\begin{tabular}{lcccccc}
\hline \multirow{2}{*}{ Returns } & \multicolumn{3}{c}{ ADF test (t-statistic) } & \multicolumn{2}{c}{ Phillips-Perron test } \\
\cline { 2 - 7 } & None & Constant & $\begin{array}{c}\text { Constant } \\
\text { and Trend }\end{array}$ & None & Constant & $\begin{array}{c}\text { Constant } \\
\text { and Trend }\end{array}$ \\
\hline BRSP & -55.266 & -55.275 & -55.267 & -55.276 & -55.280 & -55.271 \\
BRFU & -59.269 & -59.281 & -59.273 & -59.239 & -59.252 & -59.244 \\
WTISP & -56.678 & -56.684 & -56.676 & -56.881 & -56.906 & -56.897 \\
WTIFU & -42.218 & -42.231 & -42.224 & -57.169 & -57.191 & -57.183 \\
\hline
\end{tabular}

Note: Entries in bold are significant at the 1\% level. 
Table 3. CCC Estimates

\begin{tabular}{|c|c|c|c|c|c|c|c|c|c|c|}
\hline \multicolumn{11}{|c|}{ Panel a: BRSP_BRFU } \\
\hline Returns & $\mathrm{C}$ & $\mathrm{AR}$ & MA & $\varpi$ & $\alpha$ & $\beta$ & $\alpha+\beta$ & $\begin{array}{c}\text { Constant } \\
\text { conditional } \\
\text { correlation }\end{array}$ & $\begin{array}{c}\text { Log- } \\
\text { likelihood }\end{array}$ & AIC \\
\hline BRSP & $\begin{array}{c}1.878 \mathrm{e}-03 \\
(2.648)\end{array}$ & $\begin{array}{c}-0.841 \\
(-8.338)\end{array}$ & $\begin{array}{c}0.859 \\
(9.045)\end{array}$ & $\begin{array}{c}\text { 6.871e-06 } \\
(5.636)\end{array}$ & $\begin{array}{c}0.039 \\
(13.72)\end{array}$ & $\begin{array}{c}0.951 \\
(256.6)\end{array}$ & 0.990 & $\begin{array}{c}0.794 \\
(159.65)\end{array}$ & 16291.932 & -10.399 \\
\hline BRFU & $\begin{array}{c}1.343 e-03 \\
(2,930)\end{array}$ & $\begin{array}{c}-0.383 \\
(-27.87)\end{array}$ & $\begin{array}{c}0.309 \\
(21.08)\end{array}$ & $\begin{array}{c}6.299 \\
(5.691)\end{array}$ & $\begin{array}{c}0.035 \\
(9.693)\end{array}$ & $\begin{array}{c}0.953 \\
(204.2)\end{array}$ & 0.988 & & & \\
\hline \multicolumn{11}{|c|}{ Panel b: WTISP_WTIFU } \\
\hline Returns & $\mathrm{C}$ & $\mathrm{AR}$ & MA & $\varpi$ & $\alpha$ & $\beta$ & $\alpha+\beta$ & $\begin{array}{c}\text { Constant } \\
\text { conditional } \\
\text { correlation }\end{array}$ & $\begin{array}{c}\text { Log- } \\
\text { likelihood }\end{array}$ & AIC \\
\hline WTISP & $\begin{array}{c}.086 e-03 \\
(3.560)\end{array}$ & $\begin{array}{c}-0.093 \\
(-0.768)\end{array}$ & $\begin{array}{c}0.029 \\
(0.240)\end{array}$ & $\begin{array}{c}2.069 \mathrm{e}-05 \\
(15.58)\end{array}$ & $\begin{array}{c}0.083 \\
(23.90)\end{array}$ & $\begin{array}{c}0.888 \\
(244.9)\end{array}$ & 0.971 & $\begin{array}{c}0.923 \\
(550.9)\end{array}$ & 17421.123 & -11.1198 \\
\hline WTIFU & $\begin{array}{c}1.209 \mathrm{e}-03 \\
(4.005)\end{array}$ & $\begin{array}{c}-0.177 \\
(-18.21)\end{array}$ & $\begin{array}{c}0.100 \\
(8.240)\end{array}$ & $\begin{array}{c}1.978 \mathrm{e}-05 \\
(11.55)\end{array}$ & $\begin{array}{c}0.083 \\
(\mathbf{2 0 . 8 1 8})\end{array}$ & $\begin{array}{c}0.888 \\
(163.0)\end{array}$ & 0.971 & & & \\
\hline
\end{tabular}


Table 4. VARMA-GARCH Estimates

\begin{tabular}{|c|c|c|c|c|c|c|c|c|c|c|c|c|}
\hline \multicolumn{13}{|c|}{ Panel a: BRSP_BRFU } \\
\hline Returns & $\mathrm{C}$ & $\mathrm{AR}$ & MA & $\varpi$ & $\alpha_{\mathrm{BRSP}}$ & $\alpha_{\mathrm{BRFU}}$ & $\beta_{\mathrm{BRSP}}$ & $\beta_{\mathrm{BRFU}}$ & $\alpha+\beta$ & $\begin{array}{c}\text { Constant } \\
\text { conditional } \\
\text { correlation }\end{array}$ & $\begin{array}{c}\text { Log- } \\
\text { likelihood }\end{array}$ & AIC \\
\hline BRSP & $\begin{array}{c}\text { 1.492e- } \\
03 \\
(2.066)\end{array}$ & $\begin{array}{c}-0.855 \\
(-9.824)\end{array}$ & $\begin{array}{c}0.872 \\
(10.673)\end{array}$ & $\begin{array}{c}3.644 \mathrm{e}-06 \\
(0.433)\end{array}$ & $\begin{array}{c}0.069 \\
(4.590)\end{array}$ & $\begin{array}{c}-0.037 \\
(-2.424)\end{array}$ & $\begin{array}{c}0.412 \\
(3.327)\end{array}$ & $\begin{array}{c}0.712 \\
(4.585)\end{array}$ & 0.481 & $\begin{array}{c}0.803 \\
(158.566)\end{array}$ & 16348.450 & -10.432 \\
\hline BRFU & $\begin{array}{c}1.183 e- \\
03 \\
(2.634)\end{array}$ & $\begin{array}{c}-0.384 \\
(-25.856)\end{array}$ & $\begin{array}{c}0.308 \\
(21.408)\end{array}$ & $\begin{array}{c}\text { 7.749e-06 } \\
(2.481)\end{array}$ & $\begin{array}{c}-0.064 \\
(-4.946)\end{array}$ & $\begin{array}{c}0.100 \\
(6.867)\end{array}$ & $\begin{array}{c}0.212 \\
(2.364)\end{array}$ & $\begin{array}{c}0.762 \\
(9.794)\end{array}$ & 0.862 & & & \\
\hline \multicolumn{13}{|c|}{ Panel b: WTISP_WTIFU } \\
\hline Returns & $\mathrm{C}$ & AR & MA & $\varpi$ & $\alpha_{\mathrm{BRSP}}$ & $\alpha_{\mathrm{BRFU}}$ & $\beta_{\mathrm{BRSP}}$ & $\beta_{\mathrm{BRFU}}$ & $\alpha+\beta$ & $\begin{array}{c}\text { Constant } \\
\text { conditional } \\
\text { correlation }\end{array}$ & $\begin{array}{c}\text { Log- } \\
\text { likelihood }\end{array}$ & AIC \\
\hline WTISP & $\begin{array}{c}\text { 1.011e- } \\
03 \\
(3.414)\end{array}$ & $\begin{array}{c}-0.060 \\
(-0.392)\end{array}$ & $\begin{array}{c}1.303 \mathrm{e}-03 \\
(0.009)\end{array}$ & $\begin{array}{c}1.641 \mathrm{e}-05 \\
(3.382)\end{array}$ & $\begin{array}{c}0.211 \\
(21.250)\end{array}$ & $\begin{array}{c}-0.138 \\
(-20.464)\end{array}$ & $\begin{array}{c}0.305 \\
(10.436)\end{array}$ & $\begin{array}{c}0.654 \\
(19.323)\end{array}$ & 0.516 & $\begin{array}{c}0.928 \\
(583.246)\end{array}$ & 17525.095 & -11.184 \\
\hline WTIFU & $\begin{array}{c}1.143 e- \\
03 \\
(3.914)\end{array}$ & $\begin{array}{c}-0.179 \\
(-18.196)\end{array}$ & $\begin{array}{c}0.105 \\
(9.717)\end{array}$ & $\begin{array}{c}\text { 1.048e-05 } \\
(8.172)\end{array}$ & $\begin{array}{c}1.679 \\
(0.274)\end{array}$ & $\begin{array}{c}0.066 \\
(11.045)\end{array}$ & $\begin{array}{c}0.033 \\
(1.387)\end{array}$ & $\begin{array}{c}0.887 \\
(40.623)\end{array}$ & 0.953 & & & \\
\hline
\end{tabular}

Notes: (1) The two entries for each parameter are their respective parameter estimates and Bollerslev and Wooldridge (1992) robust $t$ - ratios.

(2) Entries in bold are significant at the 5\% level. 
Table 5. DCC Estimates

\begin{tabular}{|c|c|c|c|c|c|c|c|c|c|c|c|}
\hline \multicolumn{12}{|c|}{ Panel a: BRSP_BRFU } \\
\hline & $\mathrm{C}$ & $\mathrm{AR}$ & MA & $\varpi$ & $\alpha$ & $\beta$ & $\alpha+\beta$ & $\theta_{1}$ & $\theta_{2}$ & $\begin{array}{c}\text { Log- } \\
\text { likelihood }\end{array}$ & AIC \\
\hline BRSP & $\begin{array}{c}1.821 \mathrm{e}-03 \\
(2.671)\end{array}$ & $\begin{array}{c}-0.762 \\
(-3.584)\end{array}$ & $\begin{array}{c}0.776 \\
(3.765)\end{array}$ & $\begin{array}{c}\text { 7.742e-06 } \\
(5.033)\end{array}$ & $\begin{array}{c}0.053 \\
(13.851)\end{array}$ & $\begin{array}{c}0.935 \\
(189.947)\end{array}$ & 0.988 & $\begin{array}{c}0.070 \\
(\mathbf{1 8 . 7 6 6 )}\end{array}$ & $\begin{array}{c}0.916 \\
(183.616)\end{array}$ & 16424.565 & -10.483 \\
\hline BRFU & $\begin{array}{c}1.244 \mathrm{e}-03 \\
(2.789)\end{array}$ & $\begin{array}{c}-0.346 \\
(-21.576)\end{array}$ & $\begin{array}{c}0.299 \\
(18.131)\end{array}$ & $\begin{array}{c}\text { 6.012e-06 } \\
(5.156)\end{array}$ & $\begin{array}{c}0.043 \\
(11.195)\end{array}$ & $\begin{array}{c}0.946 \\
(195.999)\end{array}$ & 0.989 & & & & \\
\hline \multicolumn{12}{|c|}{ Panel b: WTISP_WTIFU } \\
\hline & $\mathrm{C}$ & $\mathrm{AR}$ & MA & $\varpi$ & $\alpha$ & $\beta$ & $\alpha+\beta$ & $\theta_{1}$ & $\theta_{2}$ & $\begin{array}{c}\text { Log- } \\
\text { likelihood }\end{array}$ & AIC \\
\hline WTISP & $\begin{array}{c}0.001 \\
(1.580)\end{array}$ & $\begin{array}{c}-0.259 \\
(-5.655)\end{array}$ & $\begin{array}{c}0.252 \\
(5.160)\end{array}$ & $\begin{array}{c}\text { 3.34E-05 } \\
(2.118)\end{array}$ & $\begin{array}{c}0.151 \\
(3.142)\end{array}$ & $\begin{array}{c}0.774 \\
(10.295)\end{array}$ & 0.925 & $\begin{array}{c}0.139 \\
(1.981)\end{array}$ & $\begin{array}{c}0.458 \\
(0.174)\end{array}$ & 17618.890 & -11.246 \\
\hline WTIFU & $\begin{array}{l}0.0003 \\
(1.796)\end{array}$ & $\begin{array}{c}0.626 \\
(6.871)\end{array}$ & $\begin{array}{c}-0.658 \\
(-8.085)\end{array}$ & $\begin{array}{c}3.98 \mathrm{E}-05 \\
(2.129)\end{array}$ & $\begin{array}{c}0.151 \\
(3.460)\end{array}$ & $\begin{array}{c}0.789 \\
(12.108)\end{array}$ & 0.940 & & & & \\
\hline
\end{tabular}

Notes: (1) The two entries for each parameter are their respective parameter estimates and Bollerslev and Wooldridge (1992) robust $t$ - ratios.

(2) Entries in bold are significant at the $5 \%$ level. 
Table 6. BEKK Estimates

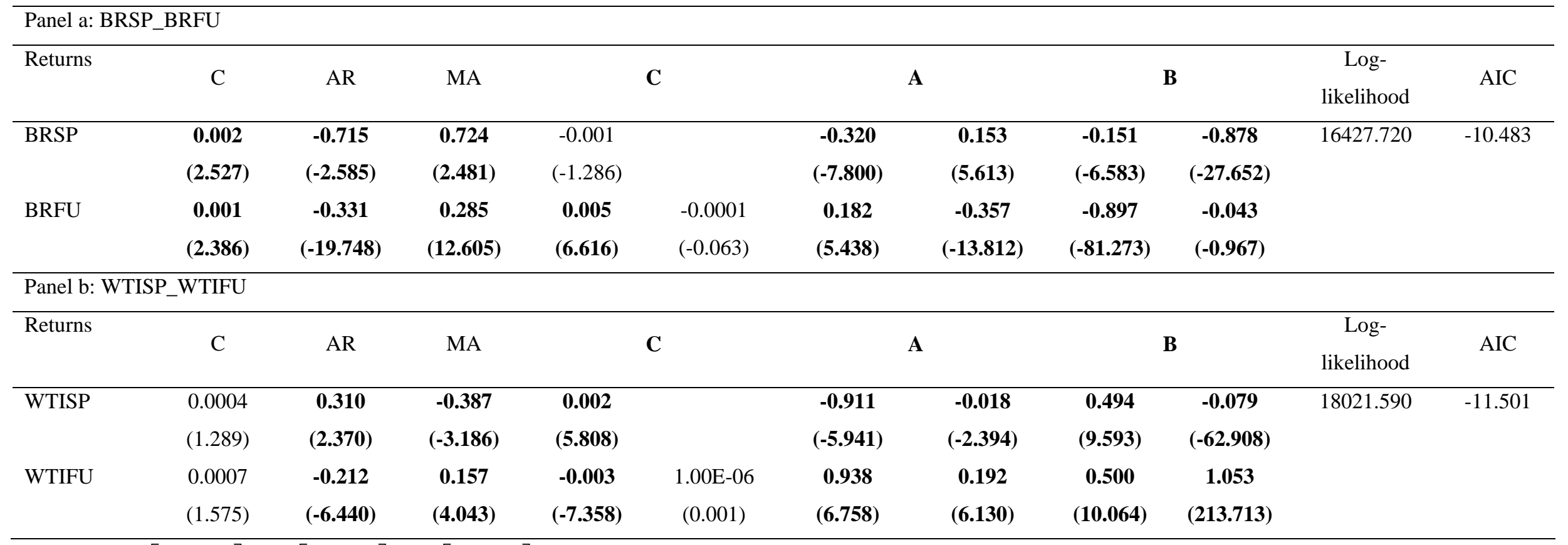

Note; (1) $\mathbf{A}=\left[\begin{array}{ll}a_{11} & a_{12} \\ a_{21} & a_{22}\end{array}\right], \mathbf{B}=\left[\begin{array}{ll}b_{11} & b_{12} \\ b_{21} & b_{22}\end{array}\right], \mathbf{C}=\left[\begin{array}{ll}c_{11} & 0 \\ c_{21} & c_{22}\end{array}\right]$ are the coefficient matrices from equation (14).

(2) The two entries for each parameter are their respective parameter estimates and Bollerslev and Wooldridge (1992) robust $t$ - ratios.

(3) Entries in bold are significant at the 5\% level. 
Table 7. Alternative Hedging Stategies

\begin{tabular}{|c|c|c|c|c|c|c|c|c|}
\hline \multirow[b]{2}{*}{ Model } & \multicolumn{2}{|c|}{ Optimal Portfolio Weights } & \multicolumn{2}{|c|}{ Average OHR } & \multicolumn{2}{|c|}{ Variance of Portfolios } & \multicolumn{2}{|c|}{ Hedge Effectiveness (\%) } \\
\hline & Brent & WTI & Brent & WTI & Brent & WTI & Brent & WTI \\
\hline CCC & 0.383 & 0.382 & 0.840 & 0.955 & $2.682 \mathrm{e}-04$ & $1.349 \mathrm{e}-04$ & 56.724 & 80.857 \\
\hline VARMA-GARCH & 0.377 & 0.377 & 0.846 & 0.956 & 2.706e-04 & $1.373 \mathrm{e}-04$ & 56.346 & 80.513 \\
\hline DCC & 0.366 & 0.478 & 0.824 & 0.923 & 2.663e-04 & $1.342 \mathrm{e}-04$ & 57.045 & 80.942 \\
\hline BEKK & 0.355 & 0.571 & 0.827 & 0.922 & $2.710 \mathrm{e}-04$ & $1.417 \mathrm{e}-04$ & 56.294 & 79.886 \\
\hline Unhedged Portfolio & & & & & 6.199e-04 & 7.046e-04 & & \\
\hline
\end{tabular}


Figure 1. Crude Oil Spot and Futures Prices for Brent and WTI
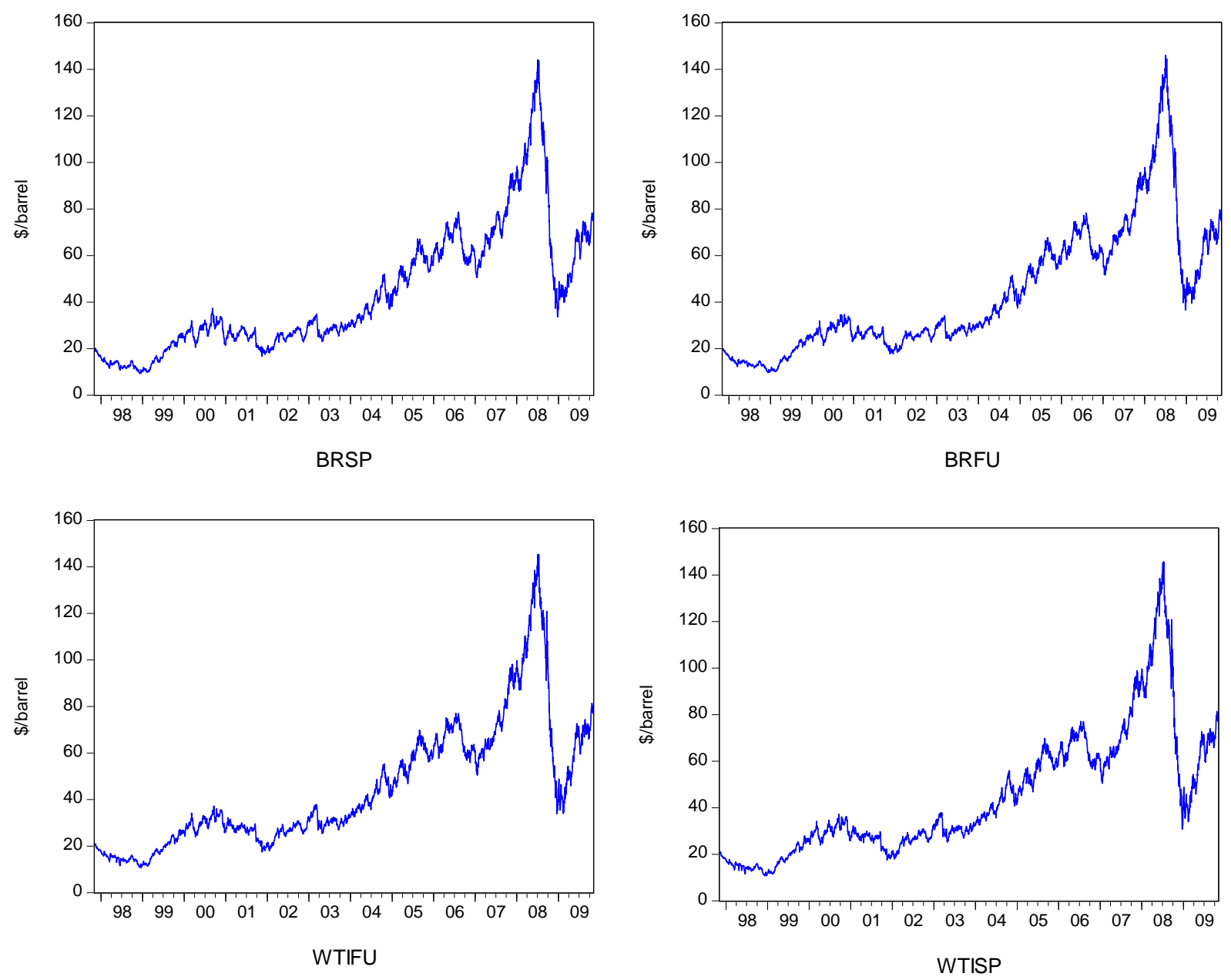
Figure 2. Logarithm of Daily Crude Oil Spot and Futures Prices for Brent and WTI
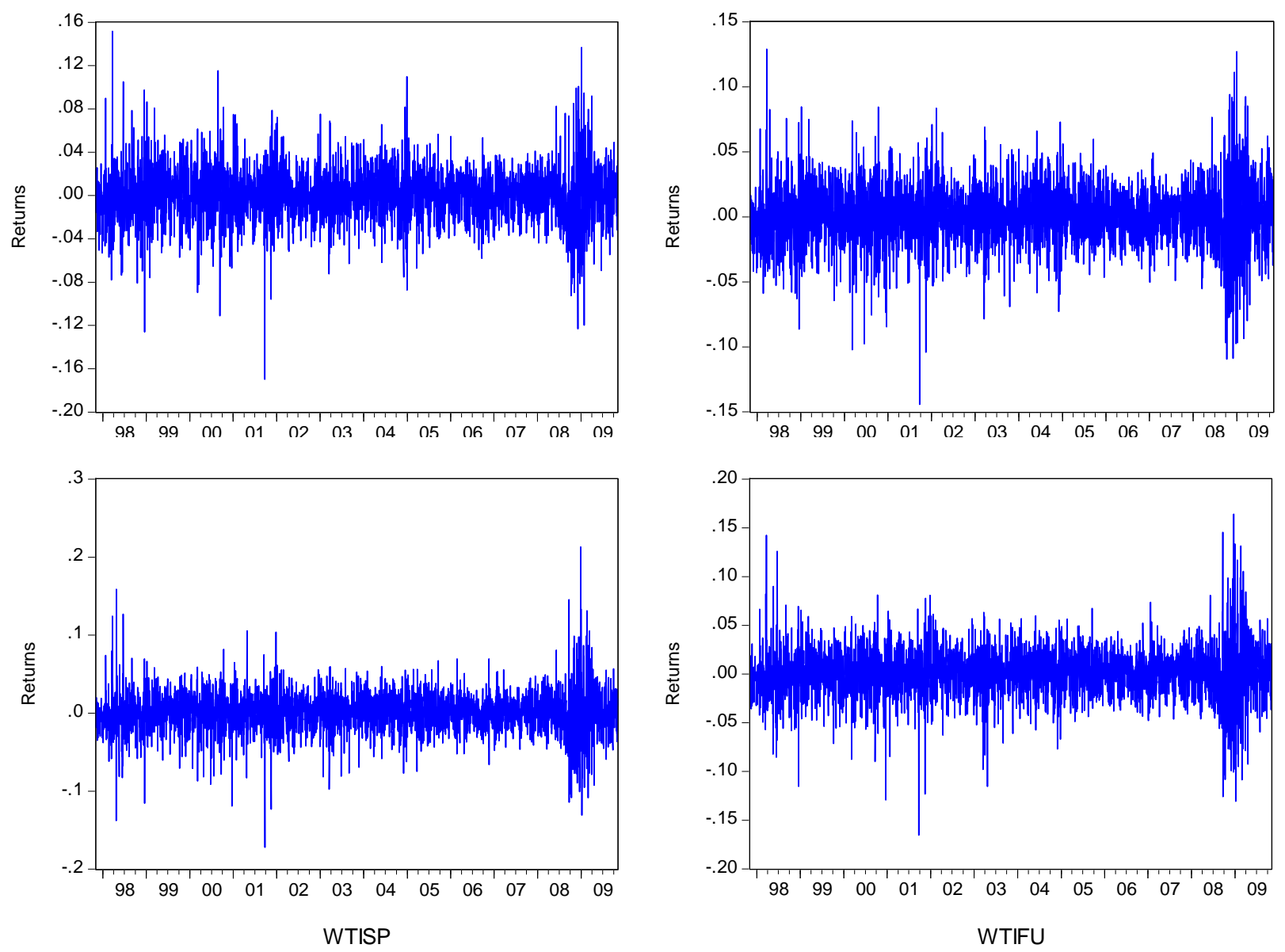
Figure 3. Estimated Conditional Volatilities of Returns for Brent and WTI
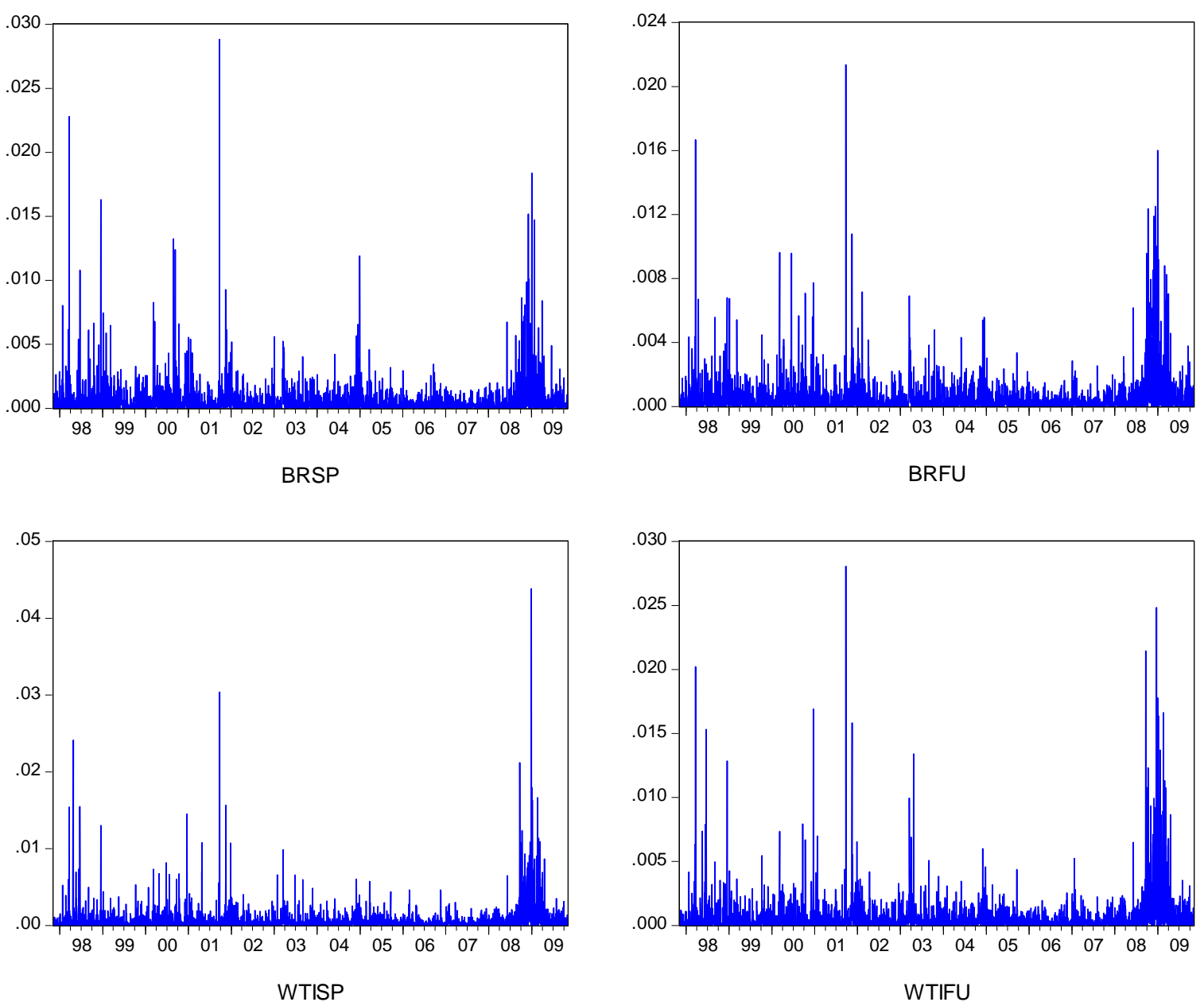
Figure 4. DCC Estimates
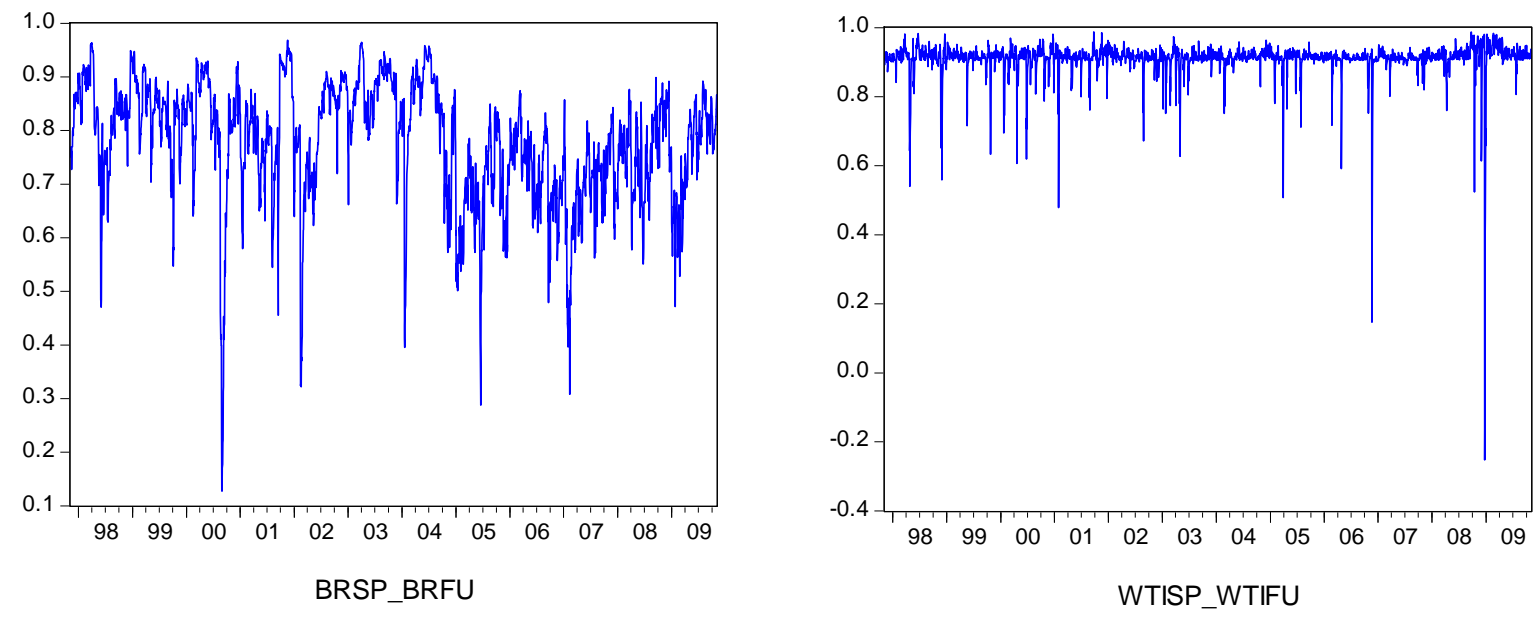
Figure 5. Optimal Hedge Ratios
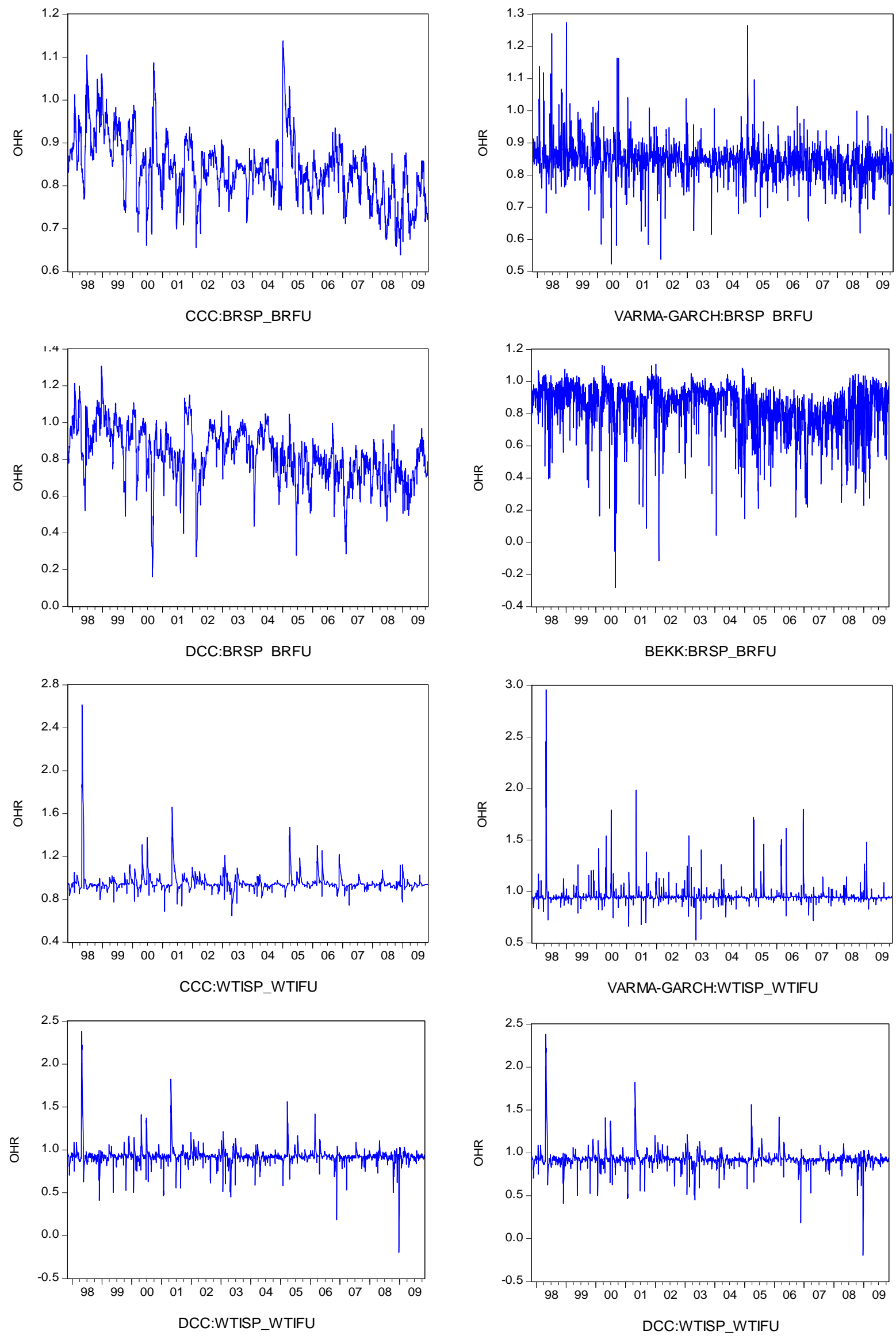